\title{
Neuroprotective effect of methanolic extract of Sargassum wightii on rotenone-induced parkinsonism-like symptoms in Wistar albino rats
}

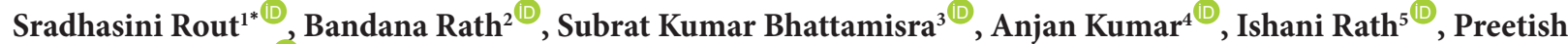 \\ Kumar Panigrahy ${ }^{6}$ \\ ${ }^{1}$ Department of Pharmacology, Roland Institute of Pharmaceutical Sciences, Berhampur, Odisha, India \\ ${ }^{2}$ Department of Pharmacology, Fakir Mohan Medical College, Balasore, Odisha, India \\ ${ }^{3}$ Department of Pharmacology Roland Institute of Pharmaceutical Sciences, Berhampur, Odisha, India \\ ${ }^{4}$ Department of Pharmaceutical chemistry, Roland Institute of Pharmaceutical Sciences, Berhampur, Odisha India \\ ${ }^{5}$ Department of Pharmacology IMS \& SUM College and Hospital, Bhubaneswar, Odisha, India \\ ${ }^{6}$ Department of Pharmacology, AIIMS Bhubaneswar, Odisha, India
}

\section{A R T I C L E I N F O}

\section{Article Type:}

Original Article

Article History:

Received: 4 June 2021

Accepted: 31 July 2021

\section{Keywords:}

Sargassum wightii

Rotenone

Parkinson's disease

Oxidative stress

Dopamine

Albino rats

\begin{abstract}
A B S T RA C T
Introduction: The pathogenesis of Parkinson's disease (PD) is multifactorial in which oxidative stress, neuroinflammation, and mitochondrial dysfunction are the leading factors. Currently, the antioxidant and anti-inflammatory agents of natural sources as neuroprotectants have raised much attention. The current study aimed to explore the neuroprotective effect of methanolic extract of Sargassum wightii in male Wistar albino rats against rotenone-induced PD.

Methods: The rats were administered with rotenone (10 $\mathrm{mg} / \mathrm{kg}$ orally) daily for 28 days to induce PD. S. wightii (200 mg/kg and $400 \mathrm{mg} / \mathrm{kg})$ and levodopa+carbidopa combination (10 mg/kg) were administered to different groups of rats one hour prior to rotenone for 28 days. Behavioral parameters (akinesia, tremor, motor coordination, and locomotor activities) and body weight were recorded on days $14^{\text {th }}$ and $28^{\text {th }}$ of drug treatment. On the $28^{\text {th }}$ day, the animals were sacrificed for the neurobiochemical analyses of brain tissue.

Results: Rotenone treatment caused a significant reduction in behavioural parameters $(P<0.001)$, neurochemical deficits $(P<0.001)$, and elevation of oxidative stress markers $(P<0.001)$ in the brain. Pre-treatment with $S$. wightii at $200 \mathrm{mg} / \mathrm{kg}$ and $400 \mathrm{mg} / \mathrm{kg}$ doses significantly attenuated the rotenone-induced behavioral alterations and restored the mitochondrial NADH dehydrogenase activity and dopamine level in the striatum $(P<0.001)$. Moreover, $400 \mathrm{mg} / \mathrm{kg}$ of $S$. wightii restored the rotenone-induced increased oxidative stress markers like malondialdehyde (MDA), superoxide dismutase (SOD), and reduced glutathione $(\mathrm{GSH})$ in the striatum $(P<0.01)$. Conclusion: $S$. wightii has provided neuroprotective effect, probably by virtue of its antioxidant and dopamine restoring potential. Hence, it may offer a promising and new therapeutic lead for the treatment of PD but needs further research.
\end{abstract}

Implication for health policy/practice/research/medical education:

Sargassum wightii has a neuroprotective effect against rotenone induced Parkinsonism like symptoms. The mechanism probably involves its promising antioxidant activity. Moreover, its dopamine and mitochondrial NADH dehydrogenase restoring effect played a pivotal role in attenuating the behavioural alterations. Hence, it might be beneficial in Parkinson's disease.

Please cite this paper as: Rout S, Rath B, Bhattamisra SK, Kumar A, Rath I, Panigrahy PK. Neuroprotective effect of methanolic extract of Sargassum wightii on rotenone-induced parkinsonism-like symptoms in Wistar albino rats. J Herbmed Pharmacol. 2021;10(4):468-475. doi: 10.34172/jhp.2021.54.

\section{Introduction}

Parkinson's disease (PD) is the second most common neurodegenerative disease that mostly affects people 60 years and above. The cardinal features of PD are akinesia, bradykinesia, resting tremor, rigidity, postural instabilities, and is often associated with cognitive dysfunction with disease progression (1). The neuropathological hallmark of $\mathrm{PD}$ is the selective and progressive degeneration of dopaminergic neurons in Substantia Nigra pars compacta, resulting in dopamine deficiency in the striatum $(2,3)$. 
Though the genetic and environmental factors pose the leading causes, other factors such as reactive oxygen species induced damage, excitotoxicity, mitochondrial dysfunctions, and inflammation-mediated cell injury have also been implicated in the etiology of PD. Over the decades, experimental evidence has focused on mitochondrial dysfunction as an important pathogenic component of PD $(3,5)$. Dopaminergic neurons are more sensitive to oxidative stress. An increase in the metabolism of dopamine generates high levels of Reactive Oxygen free radicals that cause cellular damage $(6,7)$. Rotenone, a natural pesticide, is a highly lipophilic and specific mitochondrial complex-I inhibitor. Therefore, it has been widely used as a mitochondrial poison model $(7,8)$. On chronic administration, it also induces oxidative stress. Both mitochondrial inhibition and oxidative stress contribute to dopaminergic neuronal degeneration and the development of PD-like symptoms $(9,10)$.

Levodopa has been considered as the gold standard drug therapy for PD, but its side effects on long term use are alarming. Recently, neuroprotective approaches with the use of antioxidants, antiapoptotic and anti-inflammatory compounds of natural sources have taken the upper hand in preventing disease progression in $\mathrm{PD}$.

Over the past decade, considerable attention has been focused on researches on marine macroalgae as they offer enormous resources for novel compounds. The macroalgae (seaweeds) have been identified as the largest reservoir of structurally diverse, bioactive compounds and secondary metabolites like peptides, carotenoids, phenols, terpenoids, phlorotannins, flavonoids, complex polysaccharides, phytosterols, glycolipids, vitamins, and minerals. Hence the pharmaceutical and agri-food industries have shown the demand for seaweeds as a functional food. Moreover, scientifically seaweeds have been validated for their antibacterial, antifungal, antiinflammatory, anticoagulant, antioxidant, hypolipidemic, anti-diabatic, hepatoprotective and neuroprotective activities $(11,14)$. Sargassum wightii, brown algae that shares similar phytoconstituents such as alkaloids, phenols, flavonoids, phlorotannins, has been proved as a powerful free radical scavenger (15). In our previous study, we observed the neuroprotective effect of $S$. wightii against haloperidol induced catalepsy (16). Thus, it is hypothesized that it has potential protective effect on other neurodegenerative diseases such as PD. This study aimed to evaluate the possible neuroprotective effect of methanolic extract of $S$. wightii on rotenone induced PD model in Wistar albino rats.

\section{Materials and Methods}

Animals

Male Wistar albino rats of 150-200 g body weight were maintained in the animal house of Roland Institute of Pharmaceutical Sciences, Berhampur, under ambient conditions of temperature $\left(24 \pm 1^{\circ} \mathrm{C}\right)$, relative humidity (45-55\%) and 12:12 light: dark cycle. The animals were fed with standard pellet diet and water ad libitum and were allowed to acclimatize to laboratory conditions for 7 days before the day of the experiment. With prior permission from the Institutional Animal Ethics Committee (IAEC), (Regd No: 926/PO/Re/S/06/ CPCSEA), the experimental procedures were conducted in accordance with the Guidelines of Committee for the Purpose of Control and Supervision of Experiments on Animals (CPCSEA) formulated by the Ministry of Fisheries, Animal Husbandry and Dairying, Government of India. All the experiments were conducted between 10.00 to 16.00 hours.

\section{Plant material}

The plant materials were collected as a gift sample from Micobiotech limited (Manufacturers of natural agricultural inputs) New Gundlav, Valsad, Gujarat, India. To prepare a methanolic extract of Sargassum, $40 \mathrm{~g}$ of powder sample was extracted with $400 \mathrm{~mL}$ of methanol by using Soxhlet's apparatus for 72 hours. The extract obtained was dried in the evaporator and stored at $4^{\circ} \mathrm{C}$ for further use. Different concentrations of drug solution were freshly prepared on the day of the experiment using $1 \%$ CMC suspension (17).

Drugs and chemicals

Rotenone, dopamine $\mathrm{HCl}$, and glycyl glycine buffer were purchased from Sigma-Aldrich, USA. Nitroblue-tetrazolium chloride, dithionitrobenzoic acid, thiobarbituric acid, and trichloro-acetic acid were purchased from HiMedia Laboratories Pvt. Ltd. Mumbai, India. All other chemicals were of analytical grade and purchased from standard manufacturers.

Phytochemical screening of plant extract

The methanolic extract of $S$. wightii was subjected to a phytochemical screening test in our earlier study and was found to contain polyphenols, terpenoids, tannins, flavonoids, and polysaccharides (16).

\section{Acute toxicity test}

The acute toxicity study was done in our previous study as per OECD Guidelines 423 [Limit test]. The extract at doses $5,50,1000$, and $2000 \mathrm{mg} / \mathrm{kg}$ were given orally in a stepwise manner. The animals were observed for 24 hours. No mortality or behavioral changes were observed during the study period (16).

\section{Experimental design}

Thirty Wistar albino rats were randomly divided into five groups $(n=6)$ to receive treatments as follows:

Group-I (Normal control) was administered with vehicle olive oil (1 mL/kg p.o). Group-II was treated with 
Rotenone (10 mg/kg p.o.) daily. Group-III rats (standard group) received levodopa and carbidopa combination $(10 \mathrm{mg} / \mathrm{kg}$ orally) and rotenone $(10 \mathrm{mg} / \mathrm{kg}$ p.o) $(1,6)$. Group-IV (S. wightii $200 \mathrm{mg} / \mathrm{kg}+$ rotenone $10 \mathrm{mg} / \mathrm{kg}$ ) and group-V (S. wightii $400 \mathrm{mg} / \mathrm{kg}$ + rotenone $10 \mathrm{mg} / \mathrm{kg}$ ) were considered as the test groups. All the treatments were given orally for a period of 28 days. The drugs and vehicle were given one hour before rotenone administration. Behavioral tests were performed on days 0, 14, and 28 of the study. After the last behavioral assessments on day 28 , rats were sacrificed by cervical dislocation and the brains were harvested quickly for the biochemical estimations.

\section{Behavioral assessments}

\section{Anti-Parkinson's activity}

On chronic administration of rotenone, the animals developed Parkinson's-like symptoms such as tremor and akinesia. The severity of tremor was measured by giving different scores like no tremors (score 0), occasional tremors (score 1), moderate tremors (score 2), and continuous tremors (score 3 ). To measure akinesia, the tail of the animal was held in hand and the animal was allowed to move forward on his forelimbs. The number of steps taken by the fore-limbs of the animal was counted for three minutes $(18,19)$.

\section{Motor coordination}

The motor coordination was evaluated by using the rotarod apparatus (Inco, Ambala, India). The performance was measured by the duration of animal stay on the rod in relation to the rod speed. The rats were allowed to adjust their postures and balance them on the rotating rods at different speeds. On the day of the experiment, the rats were placed individually on the rotating rod with a speed of $25 \mathrm{rpm}$, the fall-off time was recorded and the cut-off time was fixed at 180 seconds (20).

\section{Spontaneous locomotor activity}

The locomotor activity (horizontal activity) was measured using a digital photoactometer (Inco, Ambala, India). The animals were placed individually in the activity cage and acclimatized for 5 minutes. Interruption in the photo beams inside the cage by the movement of the animals represents activity count, which was recorded for five minutes (20). The chamber was swabbed with $10 \%$ ethanol each time to avoid animal odor.

\section{Biochemical estimations}

Preparation of solubilised brain mitochondrial sample

To obtain a solubilized mitochondrial sample, the method of Berman et al, was followed (21). The rats were decapitated, and the whole brains were removed quickly, washed, minced, and homogenized at $4^{\circ} \mathrm{C}$ in $10 \mathrm{~mL}$ of isolation medium $(225 \mathrm{mM}$ mannitol, $75 \mathrm{mM}$ sucrose, $5 \mathrm{mM}$ HEPES, $1 \mathrm{mM}$ EGTA, $1 \mathrm{mg} / \mathrm{mL}$ bovine serum albumin, $\mathrm{pH}$ 7.4), then centrifuged at $2000 \mathrm{~g}$ for 5 minutes. The pellets were resuspended with 10 $\mathrm{mL}$ isolation buffer and recentrifuged as above. The resulting supernatants were collected in separate tubes and centrifuged at $12000 \mathrm{~g}$ for 8 minutes. The pellets, including the fluffy synaptosomal layer, were resuspended with an isolation medium and centrifuged at $12000 \mathrm{~g}$ for 10 minutes to get brown-colored pellets. These pellets containing mitochondria without the synaptosomal layer were resuspended in $10 \mathrm{~mL}$ of isolated medium and recentrifuged as above. Finally, the mitochondrial pellets were resuspended with $50 \mu \mathrm{L}$ of medium and used as the sample.

Mitochondrial nicotinamide adenine dinucleotide dehydrogenase (NADH) (Complex-I) enzyme activity The method of King and Howard was followed for the estimation of $\mathrm{NADH}$ dehydrogenase enzyme activity. It involves catalytic oxidation (releasing $\mathrm{H}^{+}$) of $\mathrm{NADH}$ to $\mathrm{NAD}^{+}$with subsequent reduction of cytochrome $\mathrm{C}$. The reaction mixture contained $0.2 \mathrm{M}$ glycylglycine buffer $(\mathrm{pH}$ 8.5), $6 \mathrm{mM} \mathrm{NADH}$ in $2 \mathrm{mM}$ glycylglycine buffer, and 10.5 $\mathrm{mM}$ cytochrome $\mathrm{C}$. The reaction was initiated after the addition of the prepared solubilised mitochondrial sample and the absorbance was measured spectrophotometrically at $550 \mathrm{~nm}$ for 2 minutes band. The values were expressed as $\mathrm{nM} / \mathrm{mg}$ protein $(22,23)$.

\section{Dopamine assay}

Determination of dopamine was done using highperformance liquid chromatography (reverse phase method), and the total brain dopamine content was expressed in micrograms per gram of tissue by using formula (24).

Monoamine $(\mu \mathrm{g} / \mathrm{g}$ tissue $)=A T / A S \times C S \times$ dilution factor $\mathrm{AT}=$ Area under the curve for the sample, AS= Area under the curve for the standard, CS= concentration of the standard $\mu \mathrm{g} / \mathrm{mL}$ and dilution factor $=10$.

\section{Lipid peroxidation assay}

The quantitative analysis of lipid peroxidation was assayed by measuring the level of malondialdehyde (MDA) in the brain tissue following the method of Okhawa. The MDA activity was determined by measuring the absorbance of thiobarbituric acid reactive species spectrophotometrically (Shimadzu UV 1800) at $532 \mathrm{~nm}$ (25).

\section{Superoxide dismutase assay}

The superoxide dismutase (SOD) activity in brain tissue homogenates was assayed by measuring the inhibition of reduction of nitro-blue-tetrazolium following the method of Marklund et al and was expressed in terms of units/mg tissue (26). 
Reduced glutathione assay

The reduced glutathione (GSH) of brain tissue homogenates was determined by the method of Sedlak et al. The principle was based on the reduction of Ellman's reagent by $-\mathrm{SH}$ groups of GSH to form 2-nitro-smercaptobenzoic acid. The absorbance of yellow colour imparted by nitromercaptobenzoic acid anion was recorded spectrophotometrically at $412 \mathrm{~nm}$ (Shimadzu UV-1800). The amount of GSH in tissue was expressed as $\mu \mathrm{g} / \mathrm{mg}$ tissue (27).

\section{Statistical analysis}

The values were expressed as mean \pm SEM. The data were analyzed for statistical significance applying ANOVA followed by Tukey's multiple comparison tests using GraphPad Prism 7.0. A probability values less than 0.05 were considered significance.

\section{Results}

Effect of methanolic extract of Sargassum wightii on rotenone induced changes on body weight

Rotenone reduced the bodyweight of rats significantly at the end of the fourth week of treatment. Treatment with levodopa + carbidopa (10 mg/kg) body weight significantly prevented the rotenone-induced loss in body weight. Further treatment with S. wightii at $200 \mathrm{mg} / \mathrm{kg}$ and $400 \mathrm{mg} / \mathrm{kg}$ body weight also inhibited the rotenone induced loss in body weight after 28 days of treatment $(P<0.01)$ (Figure 1).

Behavioral indices

Effect of methanolic extract of Sargassum wightii on rotenone induced akinesia and tremor

On the $14^{\text {th }}$ and $28^{\text {th }}$ days of rotenone administration, the rats showed a significant increase in akinesia score to $25.83 \pm 3.38$ and $17.83 \pm 3.44$, respectively compared with normal control rats $(P<0.001)$ (Figure $2 \mathrm{~A})$. In comparison to the rotenone control group, levodopa + carbidopa (10 $\mathrm{mg} / \mathrm{kg}$ ) body weight significantly prevented rotenone- induced increase in akinesia to $48.33 \pm 4.40$ and $60.33 \pm 4.28$ on the $14^{\text {th }}$ and $28^{\text {th }}$ days, respectively $(P<0.001)$. S. wightii $200 \mathrm{mg} / \mathrm{kg}$ treatment for fourteen days did not reveal any significant change in rotenone-induced akinesia, but on the $28^{\text {th }}$ day, it showed a significant decrease in akinesia $(38.67 \pm 3.92)(P<0.01)$. S. wightii with $400 \mathrm{mg} / \mathrm{kg}$ body weight significantly reduced the akinesia both on $14^{\text {th }}$ $(46.67 \pm 3.27)(P<0.01)$ and $28^{\text {th }}$ days $(50.67 \pm 4.28)$ of treatment $(P<0.001)$ (Figure $2 A)$. However, on the $28^{\text {th }}$ day, only the higher dose of $S$. wightii $(400 \mathrm{mg} / \mathrm{kg}$ ) reduced the tremor score in rotenone-induced PD rats $(P<0.05)$ (Figure 2B).

\section{Effect of methanolic extract of Sargassum wightii on motor coordination}

The motor coordination of the animals was tested using rotarod apparatus. In comparison to the control rats, rotenone-treated rats showed a significant decrease in motor coordination on the $14^{\text {th }}$ and $28^{\text {th }}$ days of treatment $(71 \pm 9.93$ seconds and $26.8 \pm 5.17$ seconds, respectively). Levodopa + carbidopa $(10 \mathrm{mg} / \mathrm{kg})$ treated rats significantly prevented rotenone-induced changes in motor coordination activity significantly on $14^{\text {th }}$ day $124 \pm 7.97$ seconds $(P<0.001)$ and to a highly significant extent on $28^{\text {th }}$ day $159.2 \pm 9.60$ seconds $(P<0.001)$.

Sargassum wightii $200 \mathrm{mg} / \mathrm{kg}$ and $400 \mathrm{mg} / \mathrm{kg}$ body weight after 14 days of treatment did not show any significant change in motor activity as compared to the rotenone-treated control group. Nevertheless, $S$. wightii $200 \mathrm{mg} / \mathrm{kg}$ and $400 \mathrm{mg} / \mathrm{kg}$ increased the motor coordination activity after 28 days of administration to a highly significant level $94.80 \pm 11.94$ seconds and $122.6 \pm 8.52$ seconds, respectively compared to rotenonetreated group $(P<0.001)$ (Figure $3 \mathrm{~A})$.

Effect of methanolic extract of Sargassum wightii on locomotor activity

The locomotor activity of the rats in rotenone-treated group was significantly reduced on the $14^{\text {th }}$ and $28^{\text {th }}$

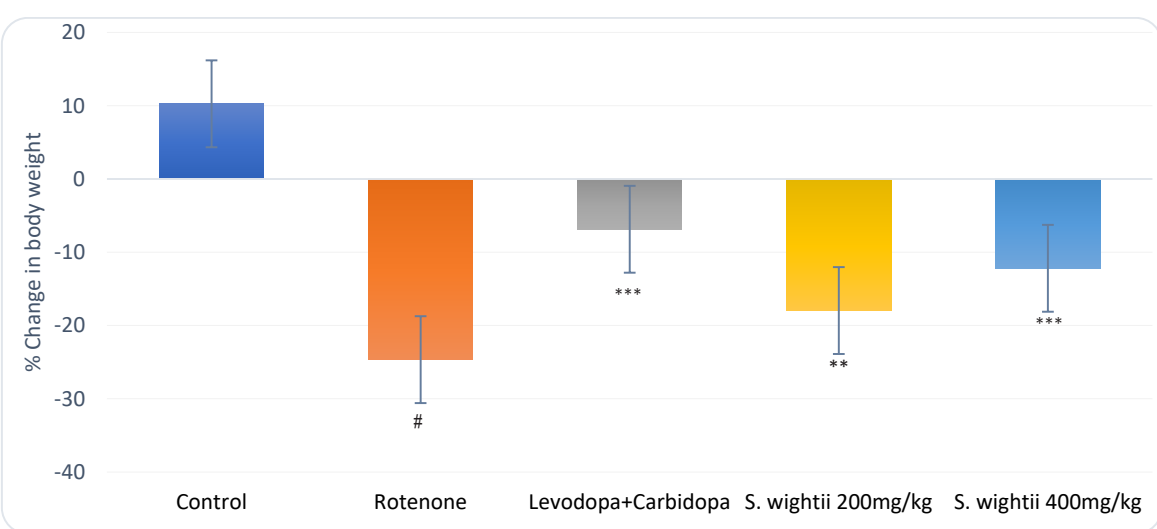

Figure 1. Effect of Sargassum wightii on body weight. One-way ANOVA followed by Tukey's multiple comparison tests was applied for analysis. \#P<0.001 compared to the vehicle control group. ${ }^{* *} P<0.01,{ }^{* *} P<0.001$ compared to the rotenone control group. 


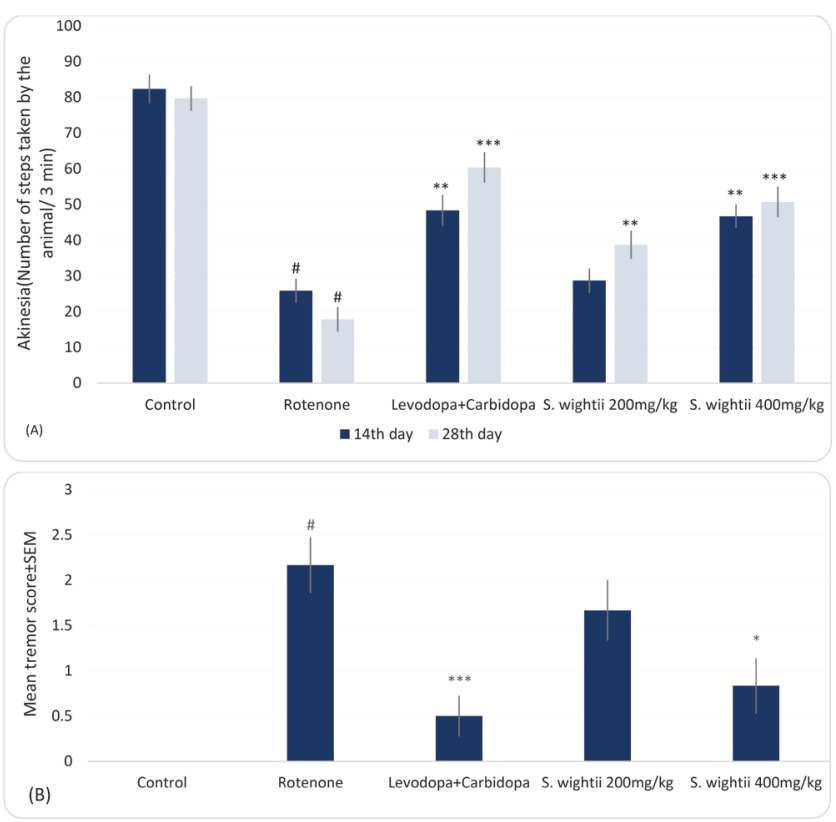

Figure 2. Effects of Sargassum wightii on akinesia (A) and tremor (B). Statistical analysis was carried out using one-way ANOVA followed by Tukey's multiple comparison tests. ${ }^{\#} P<0.001$ compared to the vehicle control group. ${ }^{*} P<0.05,{ }^{* *} P<0.01,{ }^{* *} P<0.001$ compared to the rotenone control group.

days of treatment by $64.5 \pm 7.54$ seconds and $40.5 \pm 4.05$ seconds compared to the vehicle control. Administration of levodopa + carbidopa $(10 \mathrm{mg} / \mathrm{kg})$ showed a significant increase in the locomotor activity both on the $14^{\text {th }}$ day $(140 \pm 16.33)$ and $28^{\text {th }}$ day $(182 \pm 32.57)(P<0.001)$ compared to the rotenone-treated group. S. wightii $200 \mathrm{mg} /$ $\mathrm{kg}$ treatment for fourteen days did not reveal a significant change in rotenone-induced locomotor activity, but on the $28^{\text {th }}$ day, it showed a significant increase in activity $(114 \pm 7.12)(P<0.01)$. S. wightii with $400 \mathrm{mg} / \mathrm{kg}$ body weight significantly increased the locomotor activity both on $14^{\text {th }}(140.7 \pm 14.9)(P<0.01)$ and $28^{\text {th }}$ day $(152.2 \pm 12.19)$ $(P<0.001)$ (Figure 3B).

Effect of methanolic extract of Sargassum wightii on rotenone induced biochemical changes

After 28 days of administration of rotenone, there was a significant increase in thiobarbituric acid reactive substances $(4.64 \pm 0.31 \mathrm{nM} / \mathrm{g}$ of brain tissue) but a significant decrease in mitochondrial $\mathrm{NADH}$ dehydrogenase activity $(3.86 \pm 0.027 \mathrm{nM} / \mathrm{mg}$ of protein), dopamine $(0.26 \pm 0.014 \mu \mathrm{g} / \mathrm{g})$, SOD level $(11.45 \pm 0.93 \mathrm{U} /$ $\mathrm{mg})$ and GSH $(1.97 \pm 0.19 \mu \mathrm{g} / \mathrm{g})$ in comparison to that of the control group $(P<0.001)$. Levodopa + carbidopa $(10 \mathrm{mg} / \mathrm{kg})$ significantly inhibited the rotenone-induced increase in TBAR to $2.25 \pm 0.28(\mathrm{nM} / \mathrm{g})$. The level of dopamine, SOD, and GSH were significantly elevated to $0.50 \pm 0.018(\mu \mathrm{g} / \mathrm{g}), 23.21 \pm 1.51(\mathrm{U} / \mathrm{mg})$ and $4.82 \pm 0.35$ $(\mu \mathrm{g} / \mathrm{g})$ following levodopa and carbidopa combination treatment $(P<0.001)$. Chronic administration of $S$. wightii $(400 \mathrm{mg} / \mathrm{kg}$ ) for 28 days significantly inhibited the rotenone induced rise in lipid peroxidation compared to rotenone control group $2.5 \pm 0.29(\mathrm{nM} / \mathrm{g})(P<0.01)$. Interestingly, S. wightii at 200 and $400 \mathrm{mg} / \mathrm{kg}$ significantly protected the rotenone-induced decrease in mitochondrial NADH dehydrogenase activity and dopamine level (Table 1). In comparison to the rotenone-treated group, S. wightii $(400 \mathrm{mg} / \mathrm{kg})$ treatment rats exhibited a significant increase in SOD activity $(18.34 \pm 1.48 \mathrm{U} / \mathrm{mg})$ and GSH level $(3.76 \pm 0.28 \mu \mathrm{g} / \mathrm{mg})$, respectively $(P<0.01)$ (Table 1$)$.

\section{Discussion}

Rotenone, a naturally derived pesticide, acts as a specific mitochondrial complex1 inhibitor and induces oxidative stress by increasing the formation of reactive oxygen species by its prominent mitochondrial complex inhibition and impaired ATP production. Evidence suggests that rotenone-induced PD is a suitable model as it simulates the behavioral and neuropathological features of disease due to selective degeneration of dopaminergic neurons (28-30). Oxidative stress may play a greater role in the demise of dopaminergic neurons indirectly by activating intracellular, cell death-related molecular pathways $(30,31)$. During the pathogenesis of PD, the production of reactive oxygen species damages the substantia nigra through lipid peroxidation, protein oxidation, and DNA oxidation. This phenomenon seems to be induced mainly by mitochondrial dysfunction, monoamine oxidase activation, or even by changes in the antioxidant defence system. Earlier studies postulated that the neurotoxicity induced by rotenone is a consequence of dopamine oxidation that produces free radicals and damages the dopaminergic neurons, which is the key point in the neuropathology of PD $(32,34)$. Currently seaweeds 


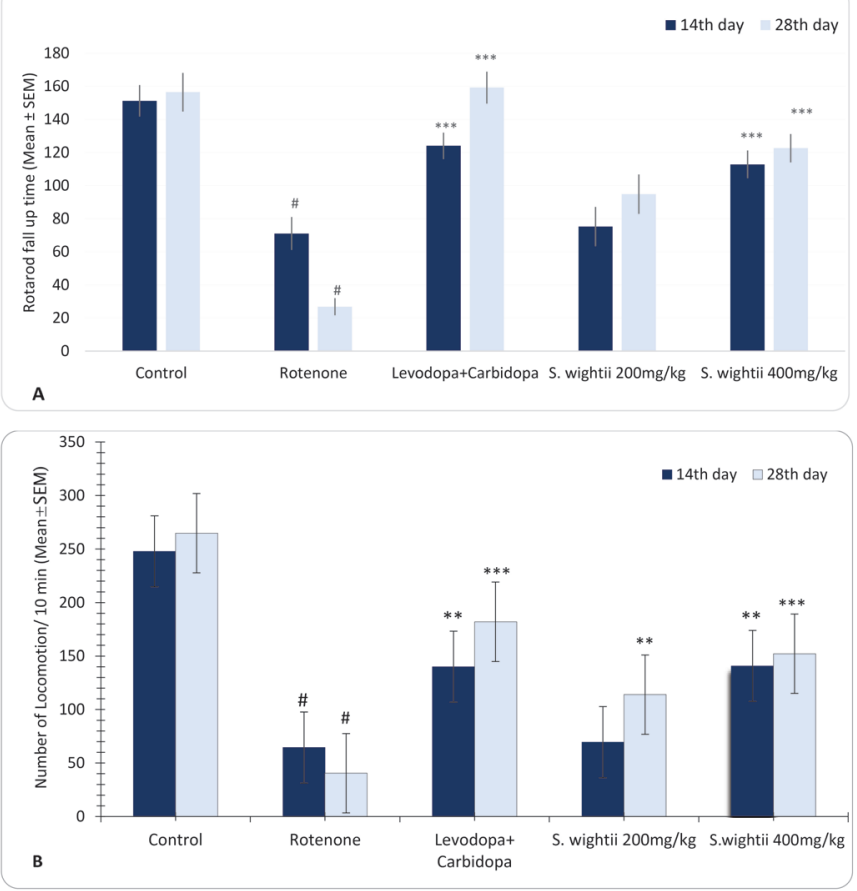

Figure 3. Effect of Sargassum wightii on rotarod fall up time (A) and locomotor activity $(B) n=6$. Statistical analysis was carried out using one-way ANOVA followed by Tukey's multiple comparison tests. ${ }^{\#} P<0.001$ when compared to the vehicle control group. ${ }^{* *} P<0.01,{ }^{* * *} P<0.001$, test group as compared to rotenone control group.

have attracted food industries as nutraceuticals for their numerous bioactive components. S. Wightii, brown seaweed has been proved to possess antioxidant and anti-inflammatory activities in our earlier study. In this context, this study was an attempt to explore the potential neuroprotective effect of methanolic extract of $S$. wightii against rotenone-induced Parkinson's-like symptoms in rats. We used levodopa and carbidopa combination as the reference standard drug for comparison.

Rotenone administration (10 $\mathrm{mg} / \mathrm{kg}$ ) for 28 days, exhibited Parkinson's-like symptoms as evidenced from an increase in akinesia, tremor, and lack of motor coordination on rotarod test and deficit in locomotor activity in Photoactometer test. Our observations were in accordance with earlier studies $(1,6)$. The reduced body weight of rotenone-treated group animal was seen in this study also corroborate with other reports. The reporters explained that this might be due to changes in liver enzymes levels, gastrointestinal dysfunction, and changes in neurotransmitter level $(35,36)$. Mitochondria are a double membrane-bounded organelle residing in the cell cytoplasm involved in cellular energy metabolism, which may play a central role in survival and apoptosis. The bio-energetic dysfunction of it is an important pathogenic component in PD $(37,38)$. In our study, rotenone depleted mitochondrial $\mathrm{NADH}$ dehydrogenase that explains rotenone-induced mitochondrial damage. Moreover, dopamine depletion reduced SOD and GSH levels and simultaneously enhanced lipid peroxidation in the rotenone-treated control rats. These may suggest that oxidative stress has been induced by rotenone (Table 1). In our observation, treatment with methanolic extract $S$. wightii both at 200 and $400 \mathrm{mg} / \mathrm{kg}$ reversed the rotenoneinduced changes in the body weight, motor coordination,

Table 1. Effect of methanolic extract of Sargassum wightii on rotenone-induced changes in brain biochemical parameters

\begin{tabular}{|c|c|c|c|c|c|}
\hline Drug and dose $(\mathrm{mg} / \mathrm{kg})$ & $\begin{array}{c}\text { Mitochondrial NADH } \\
\text { dehydrogenase activity } \\
\text { nM/g of protein }\end{array}$ & $\begin{array}{c}\text { Dopamine } \\
\text { ( } \mu \mathrm{g} / \mathrm{g} \text { tissue) }\end{array}$ & $\begin{array}{l}\text { MDA } \\
\text { (nM/g of } \\
\text { tissue) }\end{array}$ & $\begin{array}{l}\text { SOD } \\
\text { (U/mg of } \\
\text { tissue) }\end{array}$ & $\begin{array}{l}\text { GSH ( } \\
\mu \mathrm{g} / \mathrm{mg} \text { of } \\
\text { tissue) }\end{array}$ \\
\hline Vehicle-10 mL & $14.07 \pm 0.39$ & $0.64 \pm 0.014$ & $1.46 \pm 0.24$ & $25.72 \pm 1.26$ & $5.57 \pm 0.34$ \\
\hline Rotenone-10 mg/kg & $3.31 \pm 0.20^{\#}$ & $0.26 \pm 0.014^{\#}$ & $4.64 \pm 0.31^{\#}$ & $11.45 \pm 0.93^{\#}$ & $1.96 \pm 0.19^{\#}$ \\
\hline Levodopa + Carbidopa-10 mg/kg + Rotenone-10 mg/kg & $10.50 \pm 0.36^{* * *}$ & $0.50 \pm 0.018^{* * *}$ & $2.25 \pm 0.28^{* * *}$ & $23.21 \pm 1.51^{* * *}$ & $4.82 \pm 0.35^{* * *}$ \\
\hline S. wightii $200 \mathrm{mg} / \mathrm{kg}+$ Rotenone- $10 \mathrm{mg} / \mathrm{kg}$ & $5.40 \pm 0.35^{* *}$ & $0.36 \pm 0.018^{* *}$ & $3.507 \pm 0.50$ & $13.35 \pm 1.21$ & $2.49 \pm 0.26$ \\
\hline S. wightii 400 mg $/ \mathrm{kg}+$ Rotenone-10 mg/kg & $8.55 \pm 0.33^{* * *}$ & $0.41 \pm 0.014^{* * *}$ & $2.50 \pm 0.29^{* *}$ & $18.34 \pm 1.48^{* *}$ & $3.76 \pm 0.28^{* *}$ \\
\hline
\end{tabular}

Values are expressed as mean \pm SEM, $n=6$. Statistical analysis was carried out using One-Way ANOVA followed by Tukey's multiple comparison tests. $\# P<0.001$ compared to the vehicle control group. ${ }^{* *} P<0.01 ; * * P<0.001$ compared to the rotenone control group. 
locomotor activity, and akinesia; however, they were not comparable to levodopa and carbidopa combination. We also observed $S$. wightii, with both doses restored rotenone-induced dopamine and mitochondrial NADH dehydrogenase depletion (Table 1).

Evidence supporting the oxidative stress hypothesis in the pathogenesis of PD suggests that increased lipid peroxidation and reduced antioxidants such as SOD and GSH are associated with neuronal cell death in Substantia nigra (39). In this work, methanol extract of S. wightii 400 $\mathrm{mg} / \mathrm{kg}$ restored the oxidative stress biomarkers like MDA, SOD, and GSH levels, revealing its antioxidant property (Table 1). Thus, we can explain that the neuroprotective effect shown by $S$. wightii is possibly due to restoration of dopamine as well as mitochondrial function. Additionally, the prevention of neurodegeneration from oxidative stress in PD could be correlated to its potent antioxidant property. However, this research is in dearth of providing the evidence correlating the neuroprotective effect of S. wightii with other neurochemical markers specific to $\mathrm{PD}$, hence addressing further research. Also, the phytoconstituents responsible for this beneficial effect of $S$. wightii need to be isolated to provide a clue in the direction of the drug development process.

\section{Conclusion}

Results of this study conclude that $S$. wightii possesses neuroprotective activity in the animal model of PDs indicating its potential role as a novel therapeutic candidate to manage neurodegeneration and prevent PD progression. However, it needs further evaluation in different experimental and clinical models to establish its efficacy and safety in long-term use.

\section{Acknowledgments}

Authors are thankful to Professor CS Maharana, HOD Pharmacology, MKCG Medical College, Berhampur, Odisha, India for providing laboratory facility to accomplish this work.

\section{Authors' contributions}

BR designed and guided the study. SR conceived the research idea and performed the experiment following all experimental guidelines, provided the data and wrote the first draft of the manuscript. AK carried out the literature search, IR and PKP performed statistical analysis and helped in the interpretation of results, SKB supervised the study. All authors reviewed and approve the final manuscript.

\section{Conflicts of interest}

Authors declare that there are no conflicts of interest.

\section{Ethical considerations}

The experiment was conducted upon receiving approval from the Institutional Animal Ethics Committee (IAEC), Roland Institute of Pharmaceutical Sciences, Berhampur, Odisha, India (Ref No: 926/PO/Re/S/06/ CPCSEA). All the experimental procedures strictly adhered to the Guidelines of Committee for the Purpose of Control and Supervision of Experiments on Animals (CPCSEA) formulated by the Ministry of Fisheries, Animal Husbandry and Dairying, Government of India.

\section{Funding/Support}

This research received no specific grant from any funding agency and was carried out on the expense of the authors.

\section{References}

1. Jankovic J. Parkinson's disease: clinical features and diagnosis. J Neurol Neurosurg Psychiatry. 2008;79(4):36876. doi: 10.1136/jnnp.2007.131045.

2. Jagmag SA, Tripathi N, Shukla SD, Maiti S, Khurana S. Evaluation of models of Parkinson's disease. Front Neurosci. 2015;9:503. doi: 10.3389/fnins.2015.00503.

3. Sharma N, Jamwal S, Kumar P. Beneficial effect of antidepressants against rotenone induced Parkinsonism like symptoms in rats. Pathophysiology. 2016;23(2):123-34. doi: 10.1016/j.pathophys.2016.03.002.

4. Teerapattarakan N, Benya-Aphikul H, Tansawat $\mathrm{R}$, Wanakhachornkrai O, Tantisira MH, Rodsiri R. Neuroprotective effect of a standardized extract of Centella asiatica ECa233 in rotenone-induced parkinsonism rats. Phytomedicine. 2018;44:65-73. doi: 10.1016/j. phymed.2018.04.028.

5. Sharma N, Rao SP, Kalivendi SV. The deglycase activity of DJ-1 mitigates $\alpha$-synuclein glycation and aggregation in dopaminergic cells: role of oxidative stress mediated downregulation of DJ-1 in Parkinson's disease. Free Radic Biol Med. 2019;135:28-37. doi: 10.1016/j. freeradbiomed.2019.02.014.

6. Ittiyavirah SR, Ruby R. Effect of hydro-alcoholic root extract of Plumbago zeylanica L. alone and it's combination with aqueous leaf extract Camellia sinensis on rotenone induced parkinsonism. Int J Res Ayurveda Pharm. 2014;5(4):494501.

7. Sharma S, Deshmukh R. Vinpocetine attenuates MPTPinduced motor deficit and biochemical abnormalities in Wistar rats. Neuroscience. 2015;286:393-403. doi: 10.1016/j. neuroscience.2014.12.008.

8. Saravanan KS, Sindhu KM, Senthilkumar KS, Mohanakumar KP. L-deprenyl protects against rotenone-induced, oxidative stress-mediated dopaminergic neurodegeneration in rats. Neurochem Int. 2006;49(1):28-40. doi: 10.1016/j. neuint.2005.12.016.

9. Balakrishnan R, Elangovan N, Mohankumar T, Nataraj J, Manivasagam T, Justin Thenmozhi A, et al. Isolongifolene attenuates rotenone-induced mitochondrial dysfunction, oxidative stress and apoptosis. Front Biosci (Schol Ed). 2018;10:248-61. doi: 10.2741/s513.

10. Zhang X, Du L, Zhang W, Yang Y, Zhou Q, Du G. Therapeutic effects of baicalein on rotenone-induced Parkinson's disease through protecting mitochondrial function and biogenesis. Sci Rep. 2017;7(1):9968. doi: 10.1038/s41598-017-07442-y.

11. Nisticò R, Mehdawy B, Piccirilli S, Mercuri N. Paraquatand rotenone-induced models of Parkinson's disease. 
Int J Immunopathol Pharmacol. 2011;24(2):313-22. doi: $10.1177 / 039463201102400205$.

12. Gupta S, Abu-Ghannam N. Recent developments in the application of seaweeds or seaweed extracts as a means for enhancing the safety and quality attributes of foods. Innov Food Sci Emerg Technol. 2011;12(4):600-9. doi: 10.1016/j. ifset.2011.07.004.

13. Sankar R, Murugan A, Sivakumar V. Anti-inflammatory, Anti-ulcer, Antipyretic, Analgesic and Cns Stimulant Activities of Marine Bryozoan Zoobotryon verticillatum. Pharmacologia. 2013;4(1):15-21. doi: 10.5567/ pharmacologia.2013.15.21.

14. Zhang J, Tiller C, Shen J, Wang C, Girouard GS, Dennis $\mathrm{D}$, et al. Antidiabetic properties of polysaccharideand polyphenolic-enriched fractions from the brown seaweed Ascophyllum nodosum. Can J Physiol Pharmacol. 2007;85(11):1116-23. doi: 10.1139/y07-105.

15. Syad AN, Shunmugiah KP, Kasi PD. Antioxidant and anticholinesterase activity of Sargassum wightii. Pharm Biol. 2013;51(11):1401-10. doi: 10.3109/13880209.2013.793721.

16. Rout S, Rath B, Bhattamisra SK, Kumar A, Rath S. Neuroprotective effect of methanolic extract of Sargassum wightii on haloperidol induced catalepsy and tardive dyskinesia in Albino rats. Int $\mathrm{J}$ Pharm Pharm Sci. 2020;12(3):1-6. doi: 10.22159/ijpps.2020v12i3.36518.

17. Kolanjinathan K, Saranraj P. Pharmacological efficacy of marine seaweed Gracilaria edulis extracts against clinical pathogens. Glob J Pharmacol. 2014;8(2):268-74. doi: 10.5829/idosi.gjp.2014.8.2.83254.

18. Sarkar S, Thomas B, Muralikrishnan D, Mohanakumar KP. Effects of serotoninergic drugs on tremor induced by physostigmine in rats. Behav Brain Res. 2000;109(2):187-93. doi: 10.1016/s0166-4328(99)00171-0.

19. Salama M, Helmy B, El-Gamal M, Reda A, Ellaithy A, Tantawy D, et al. Role of L-thyroxin in counteracting rotenone induced neurotoxicity in rats. Environ Toxicol Pharmacol. 2013;35(2):270-7. doi: 10.1016/j.etap.2012.12.008.

20. Kulkarni SK. Handbook of Experimental Pharmacology. 3rd ed. Delhi: Vallabh Prakashan; 2005. p. 17-8.

21. Berman SB, Hastings TG. Dopamine oxidation alters mitochondrial respiration and induces permeability transition in brain mitochondria: implications for Parkinson's disease. J Neurochem. 1999;73(3):1127-37. doi: 10.1046/j.1471-4159.1999.0731127.x.

22. King TE, Howard RL. Preparations and properties of soluble NADH dehydrogenases from cardiac muscle. Methods Enzymol. 1967;10:275-94. doi: 10.1016/00766879(67)10055-4.

23. Hastings TG, Lewis DA, Zigmond MJ. Role of oxidation in the neurotoxic effects of intrastriatal dopamine injections. Proc Natl Acad Sci U S A. 1996;93(5):1956-61. doi: 10.1073/ pnas.93.5.1956.

24. Pagel P, Blome J, Wolf HU. High-performance liquid chromatographic separation and measurement of various biogenic compounds possibly involved in the pathomechanism of Parkinson's disease. J Chromatogr B Biomed Sci Appl. 2000;746(2):297-304. doi: 10.1016/s03784347(00)00348-0.

25. Ohkawa H, Ohishi N, Yagi K. Assay for lipid peroxides in animal tissues by thiobarbituric acid reaction. Anal Biochem. 1979;95(2):351-8. doi: 10.1016/0003-2697(79)90738-3.
26. Marklund S, Marklund G. Involvement of the superoxide anion radical in the autoxidation of pyrogallol and a convenient assay for superoxide dismutase. Eur J Biochem. 1974;47(3):469-74. doi: 10.1111/j.1432-1033.1974. tb03714.x.

27. Sedlak J, Lindsay RH. Estimation of total, proteinbound, and nonprotein sulfhydryl groups in tissue with Ellman's reagent. Anal Biochem. 1968;25(1):192-205. doi: 10.1016/0003-2697(68)90092-4.

28. Günaydın C, Avcı B, Bozkurt A, Önger ME, Balcı H, Bilge SS. Effects of agomelatine in rotenone-induced Parkinson's disease in rats. Neurosci Lett. 2019;699:71-6. doi: 10.1016/j. neulet.2019.01.057.

29. Chiu CC, Yeh TH, Lai SC, Wu-Chou YH, Chen $\mathrm{CH}$, Mochly-Rosen D, et al. Neuroprotective effects of aldehyde dehydrogenase 2 activation in rotenone-induced cellular and animal models of parkinsonism. Exp Neurol. 2015;263:24453. doi: 10.1016/j.expneurol.2014.09.016.

30. Nicholls DG. Oxidative stress and energy crises in neuronal dysfunction. Ann N Y Acad Sci. 2008;1147:53-60. doi: 10.1196/annals.1427.002.

31. Götz ME, Künig G, Riederer P, Youdim MB. Oxidative stress: free radical production in neural degeneration. Pharmacol Ther. 1994;63(1):37-122. doi: 10.1016/0163-7258(94)900558.

32. Zhou C, Huang Y, Przedborski S. Oxidative stress in Parkinson's disease: a mechanism of pathogenic and therapeutic significance. Ann N Y Acad Sci. 2008;1147:93104. doi: 10.1196/annals.1427.023.

33. Abdelkader NF, Arafa NM, Attia AS, Ain-Shoka AA, Abdallah DM. Pyrrolidine dithiocarbamate ameliorates rotenone-induced Parkinson's disease in rats. Bull Fac Pharm Cairo Univ. 2017;55(1):107-13. doi: 10.1016/j. bfopcu.2016.11.003.

34. Alam M, Schmidt WJ. Rotenone destroys dopaminergic neurons and induces parkinsonian symptoms in rats. Behav Brain Res. 2002;136(1):317-24. doi: 10.1016/s01664328(02)00180-8.

35. de Farias CC, Maes M, Bonifácio KL, Bortolasci CC, de Souza Nogueira A, Brinholi FF, et al. Highly specific changes in antioxidant levels and lipid peroxidation in Parkinson's disease and its progression: disease and staging biomarkers and new drug targets. Neurosci Lett. 2016;617:66-71. doi: 10.1016/j.neulet.2016.02.011.

36. Edwards LL, Quigley EM, Pfeiffer RF. Gastrointestinal dysfunction in Parkinson's disease: frequency and pathophysiology. Neurology. 1992;42(4):726-32. doi: 10.1212/wnl.42.4.726.

37. von Wrangel C, Schwabe K, John N, Krauss JK, Alam M. The rotenone-induced rat model of Parkinson's disease: behavioral and electrophysiological findings. Behav Brain Res. 2015;279:52-61. doi: 10.1016/j.bbr.2014.11.002.

38. Van Laar VS, Berman SB. The interplay of neuronal mitochondrial dynamics and bioenergetics: implications for Parkinson's disease. Neurobiol Dis. 2013;51:43-55. doi: 10.1016/j.nbd.2012.05.015.

39. Bhangale JO, Acharya SR. Anti-Parkinson activity of petroleum ether extract of Ficus religiosa (L.) leaves. Adv Pharmacol Sci. 2016;2016:9436106. doi: $10.1155 / 2016 / 9436106$. 